\title{
Automobiles Branding Methods and Materials in Ghana
}

\author{
${ }^{1}$ Obed Persie Appiah-Kubi, ${ }^{2}$ Kafui Kwesi Agyeman (PhD), ${ }^{3}$ Frederick Ampah Clement and ${ }^{4}$ Harold Awuley Quaye \\ $1,2,3,4$ Department of Integrated Rural Art and Industry, Faculty of Art, \\ Kwame Nkrumah University of Science and Technology, Kumasi, Ghana
}

\begin{abstract}
Academic institutions in Ghana like the KNUST and University of Ghana, to mention but a few, have accepted vehicle branding especially on their institutional vehicles. This has helped these institutions to market themselves over the years. Although these academic institutions and other agencies do vehicle branding, preliminary findings suggested that, the knowledge on the methods of branding and the basic materials used for each branding method is not widely known to many. This is the primary motivation for the conduct of this study. This study aimed at identifying the methods and materials used for branding the automobiles. To achieve this aim, the methods of vehicle branding were identified and the basic materials used for each vehicle branding method. The qualitative research methods, characterized by the descriptive research design were employed in the study. In this 300 respondents from KNUST and University of Ghana were selected for the study, 150 from each university. They were sampled and interviewed using the snowball, simple random and purposive sampling techniques. The study revealed three main methods used in branding vehicles in the communities: vinyl graphics, metal impression and magnetic branding. Their corresponding materials used are polyvinyl chloride, metal and magnetic materials respectively. From both universities, the study also revealed that the most commonly used method of branding in descending order were vinyl graphics, metal impression and magnetic branding. The study make five recommendations regarding further research areas; approaches that may be more durable for some of the methods; and improvement on vehicle branding with trendy technologies.
\end{abstract}

Keywords:- Branding, Automobile, Vinyl Graphics, Magnetic Brands, Metal Impressions

\section{INTRODUCTION}

Vehicle branding according to Shimp (2008) is a valuable tool for promoting a person, business or a product. Brand is defined by Schmidt (2005), as any unique design, sign, symbol, words, or a combination of these, employed in creating an image that identifies a product or a company and differentiates it from competitors. It is considerably more than a symbol, sign, emblem or a name, as it embodies the full nature and character of an institution (Davis, 2009).
Schmidt (2005) and the business dictionary (2017) defines branding as when that idea or image is marketed so that it becomes recognizable by people, and identified with a certain service, people or product. Globally, individuals and corporate institutions have come to understand the need to brand their vehicles (Perry, 2013; Wong, 2005). Branding is important because it brings about innovation, increased security, high visibility, and increased night-time safety therefore averting the chance of accident (Wong, 2005).

The art of branding vehicles come in many categories with the aim of promoting an organization, person, or a product. They include; religious, political, patriotic, profession and trade, landscape, commercial, secular, humorous, to mention but a few (Perry, 2013; Wong, 2005).

As individuals and corporate institutions across the globe have realized the importance and the need to do vehicle branding, academic institutions in Ghana like the Kwame Nkrumah University of Science and Technology (KNUST), University of Ghana (Legon), University of Cape Coast (UCC), to mention a few, have accepted vehicle branding which are mostly seen on their institution or facility buses. This has helped these institutions to gain more recognition over the years. Again, through branding, these institutions have specially designed identification tags or stickers for their staff to be fixed on the windscreen of their vehicle to easily identify them in the community in which they live in. This same staff identification sticker which is a way of branding, has currently been improved electronically as introduced by the KNUST and Legon to give their staff the power to enter into some restricted areas within their campuses via electronic vehicular access control systems.

Although these academic institutions and other sales and marketing companies do vehicle branding as a matter of necessity and pleasure, the knowledge on the methods of branding and basic materials used for each branding method is not known to many.

This study aimed at investigation into the methods and materials used for branding automobiles.

The preliminary studies took place in the University of Ghana, Legon in the Greater Accra Region of Ghana and then the Kwame Nkrumah University of Science and Technology, Kumasi (KNUST). These are institutions that have more advanced in the design and use of vehicle brands 
and identification tags that identify them in their respective communities and beyond.

This study was expected to educate people on the methods of branding and again help them with the knowledge of the basic materials used for each branding method. Again, the study sort to educate artists in the vehicle branding business especially those who do vinyl graphics and metal impression branding for corporate institutions in order to indulge in well informed approaches. Also, the study is expected to underpin data collection and analyses of developing trends in vehicle identification and branding.

\section{METHODS}

The survey and content analyses research designs under the qualitative research methods were employed in this study to seek information on the methods of automobile branding and the basic materials used for each branding method. In this regard, the descriptive research design was adopted for this study and was used to analyze the various vehicle branding methods and how they differ from one another. Reviews, interviews and observations were the instruments used to collect data for the study.
Apart from the review of information, three hundred respondents consisting of vehicle user of the University of Ghana (UG) and the Kwame Nkrumah University Science and Technology, Kumasi communities were sampled randomly and interviewed through a structured questionnaires. The study targeted and accrued One hundred and fifty (150) respondents from each institution. Obtained results were grouped according to respondents' responses regarding types of car branding in their community and the materials they were made of. In order to ascertain the most popular of the brandings they know, the first response of each respondent was used in the analyses.

\section{RESULTS}

Apart from the access control chips identified to be used the two institution, the survey produced three methods of branding that are known to the communities. These are: magnetic branding, metal impression branding, and vinyl graphics branding. as illustrated in figure 1, out of the one hundred and fifty (150) respondents from University of Ghana, twelve (12) representing $8 \%$ answered that they know of magnetic branding on vehicles. Thirty-nine (39) of the respondents, representing $26 \%$ also stated they know of metal impression branding on vehicles. The rest of the respondents (99), representing $66 \%$ also indicated that they know of vinyl graphics branding.

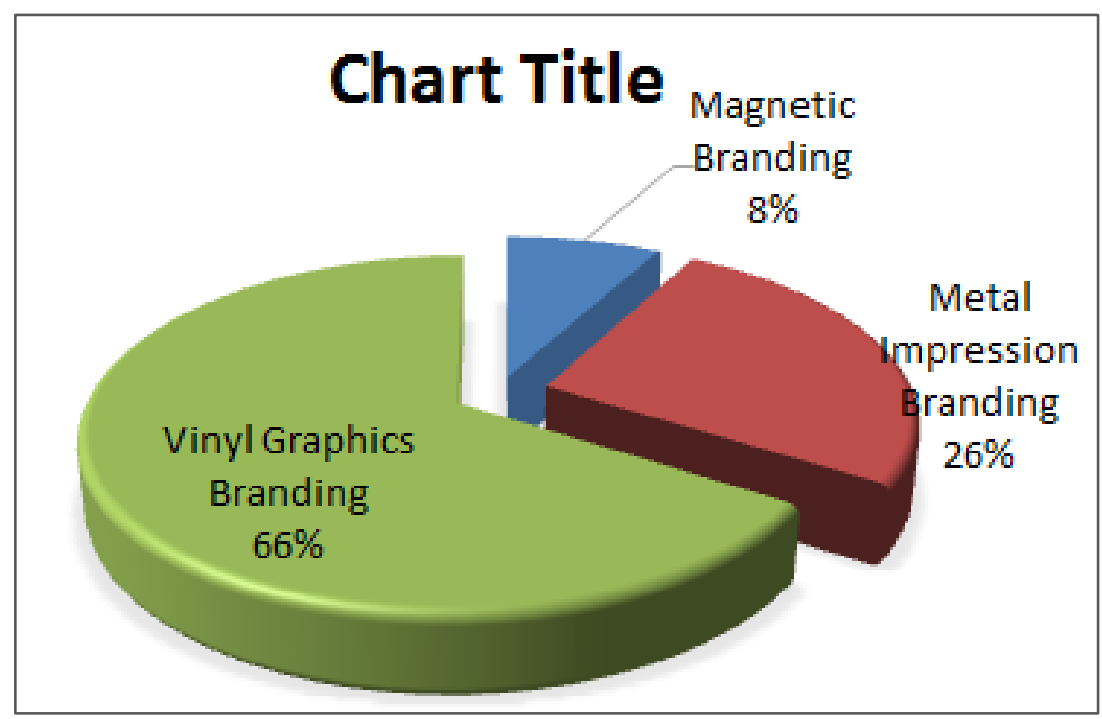

Fig 1:- Response from staff of University of Ghana on the knowledge of vehicle branding methods

On the other hand, out of the one hundred and fifty (150) respondents from KNUST, 15 representing $10 \%$ answered that they know of magnetic branding on vehicles. 45 of the respondents, representing $30 \%$ also stated they know of metal impression branding on vehicles. The rest of the respondents (90), representing $60 \%$ also indicated that they know of vinyl graphics branding. This is seen in figure 2 of this paper. 


\section{Chart Title}

国 Magnetic Branding $\mathbf{0}$ Metal Impression Branding $\mathbf{a}$ Vinyl Graphics Branding

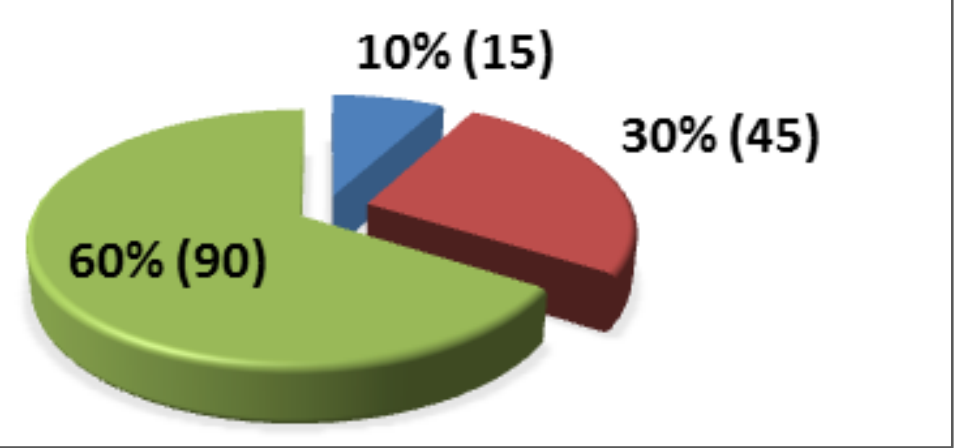

Fig 2:- Response from staff of KNUST on the knowledge of vehicle branding methods

In table 1: the relation of the analyses of the institutions suggests that Vinyl Graphics Branding is the most popular and more practiced the rest. It records 63\% regarding the knowledge of the respondents. The second on this scale is the Metal Impression Branding recording 28\% and then the least: Magnetic Branding recording 9\%. These methods of branding are highlighted in the next chapter.

\begin{tabular}{|c|c|c|c|}
\hline \multicolumn{4}{|c|}{ RESPONSE ON THE MATERIALS USED FOR EACH BRANDING METHOD } \\
\hline Methods of branding & Materials used & $\begin{array}{l}\text { No. of responses } \\
\text { (UG \& KNUST) }\end{array}$ & $\%$ \\
\hline Vinyl Graphics Branding & Polyvinyl chloride materials & 189 & 63 \\
\hline Metal Impression Branding & Metal & 84 & 28 \\
\hline \multirow[t]{2}{*}{ Magnetic Branding } & $\begin{array}{l}\text { Polyvinyl chloride materials and magnetic } \\
\text { bar }\end{array}$ & 27 & 9 \\
\hline & Total & 300 & $100 \%$ \\
\hline
\end{tabular}

Table 1:- Responses obtained from staff of UG and KNUST on materials used for each vehicle branding method

\section{A. Magnetic Branding}

With this method of automobile branding, a designed logo, letters, emblem or a combination of an institution or an individual customized design is produced from either metal or plastic for the purpose of sticking onto a vehicle by a magnetic force. Looking at the figures 3 and 4, the back of the designed logo or emblem has a magnet or magnetic linen to attract and stick to steel bodies of vehicles. These may combine with adhesives to give a more permanent effect.

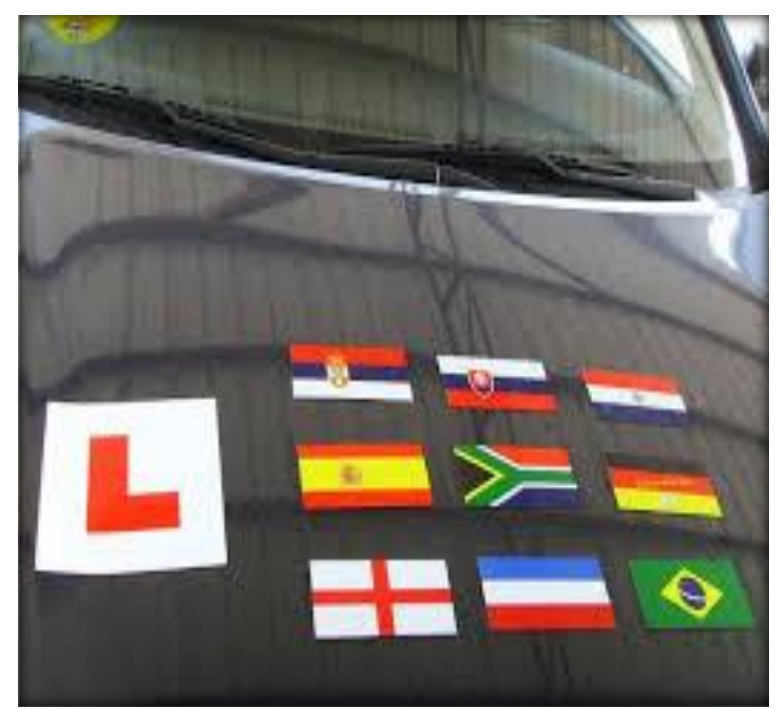

Fig 3:- Shows magnetic badges of some countries stuck to the bonnet of a vehicle (Source: $\underline{w w . e b a y . c o m)}$ 


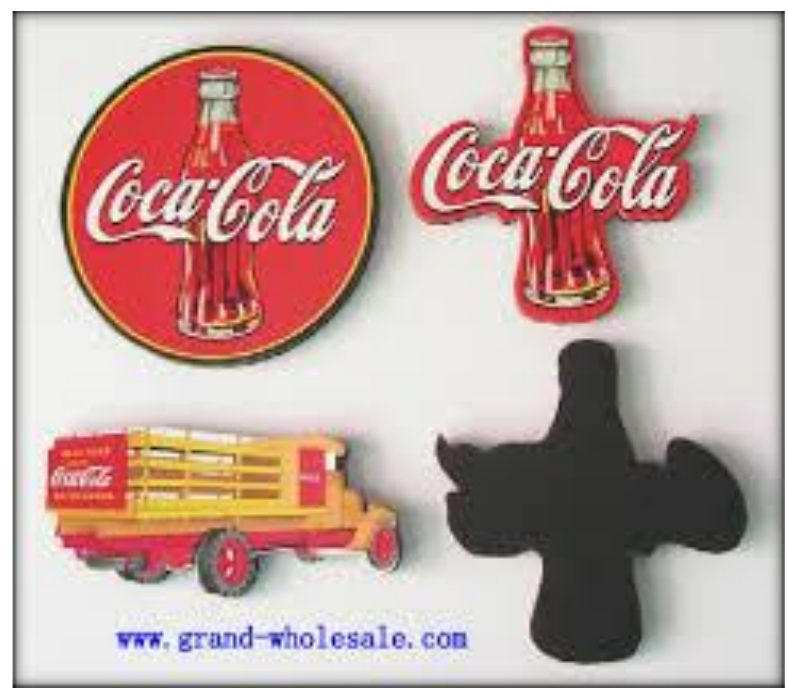

Fig 4:- Shows magnetic badges of Coca-Cola

(Source: www.alibaba.com)

\section{B. Vinyl Graphics Branding}

Unlike the magnetic branding method, the vinyl graphics branding of automobile is usually a design of logo, an abstract, picture or letters printed on a polyvinyl chloride material intended to be stacked onto a surface of vehicle. With this method of branding which now appears very common nationwide, make use of well-designed wrap of an institution created to promote an institution's products or services. Most institutions in Ghana use this method of vehicle branding as it can be seen on the windscreens of staff vehicle in a form of stickers. Individual also customize their name or preferred designs that are printed on polyvinyl chloride material to be used as wrap around vehicles. Examples are presented in figures 3 to 7 . Figure 3 and 4 shows example of wrapped vehicles. Figure 5 and 6 represents the sticking examples and figure 7: the transfer type.

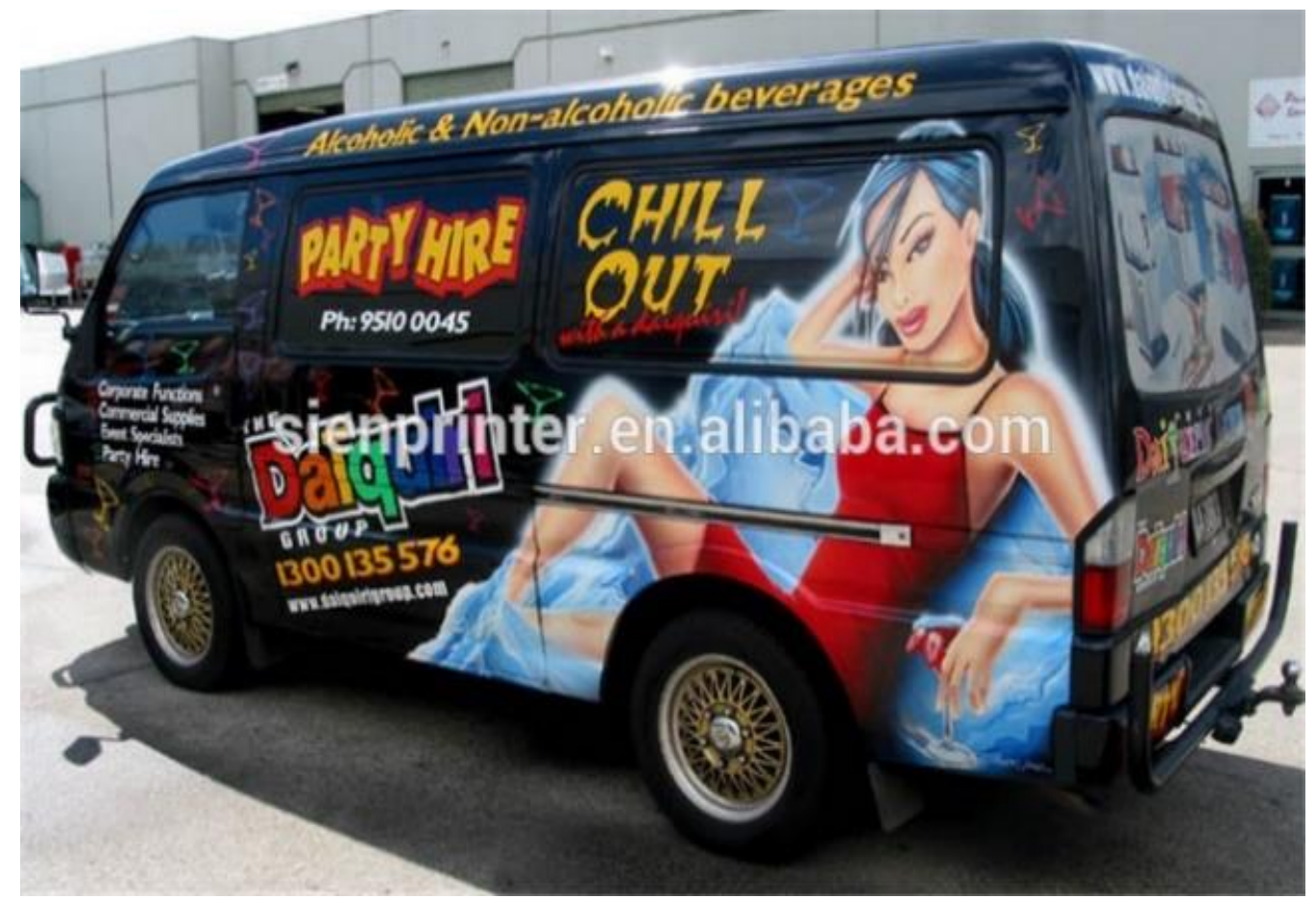

Fig 5:- Shows an advertisement on vinyl designed material wrapped around a van(Source: www.ebay.com) 


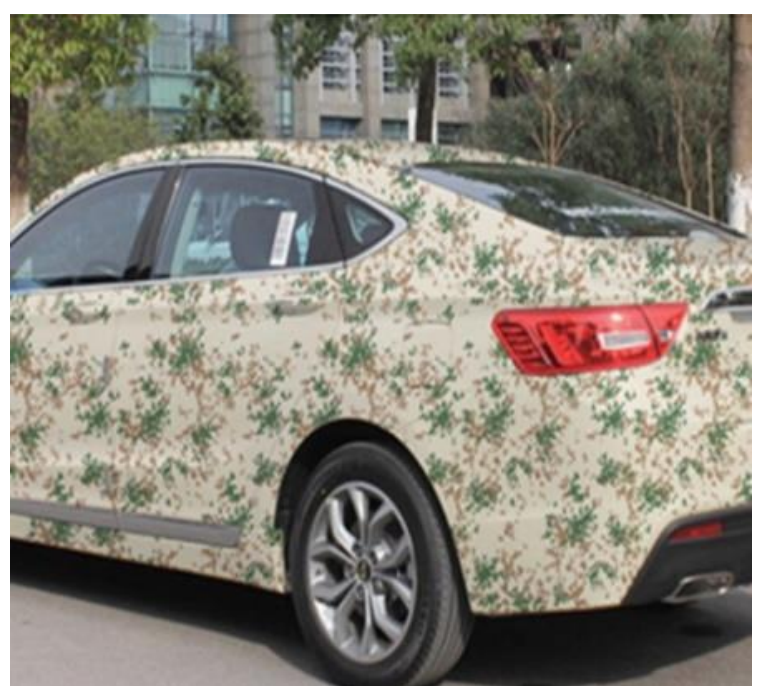

Fig 6:- Shows customized camouflagevinyl wrapped around a vehicle.

(Source: $w$ ww.alibaba.com)

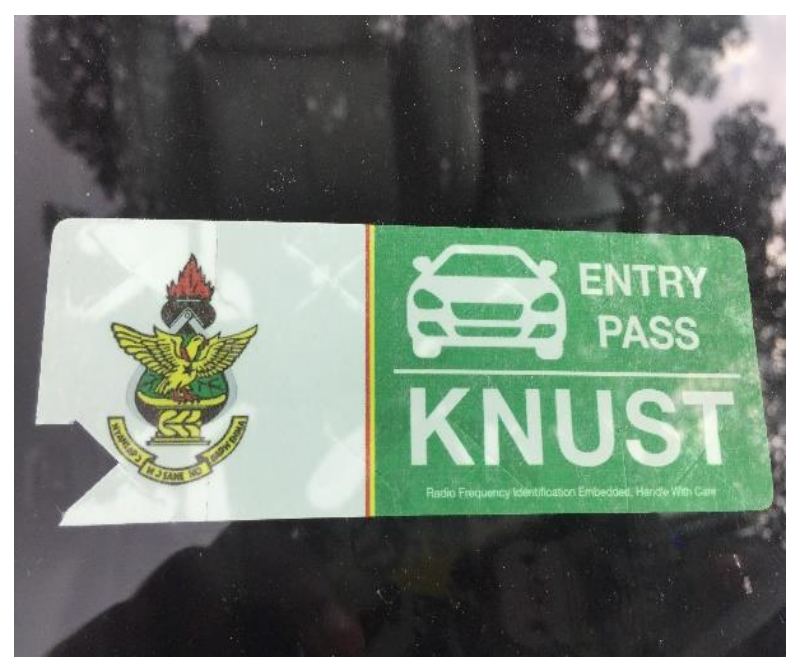

Fig 7:- Shows the KNUST vehicle identification Brand fixed on a widescreen of a vehicle

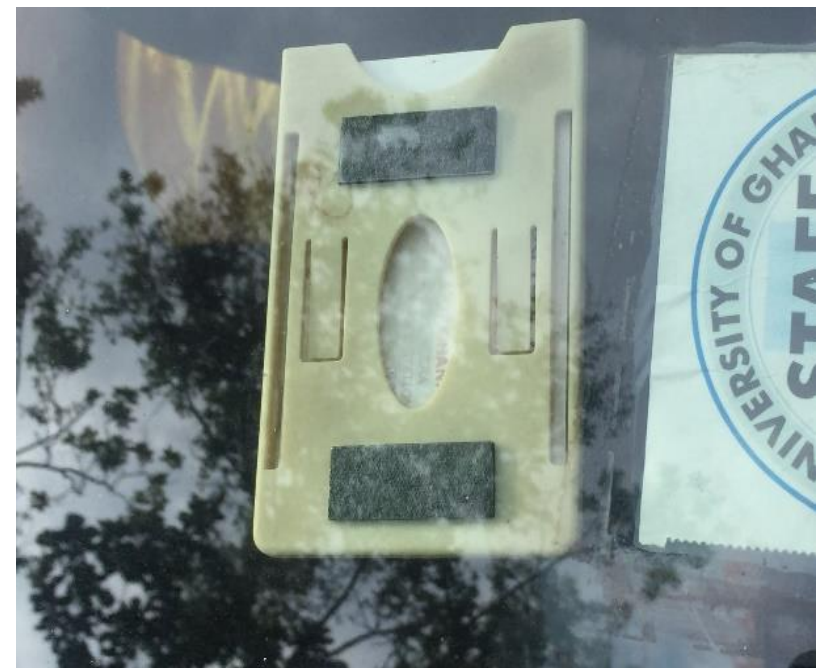

Fig 8:- Shows the University of Ghana vehicle Identification brand fixed on a car 


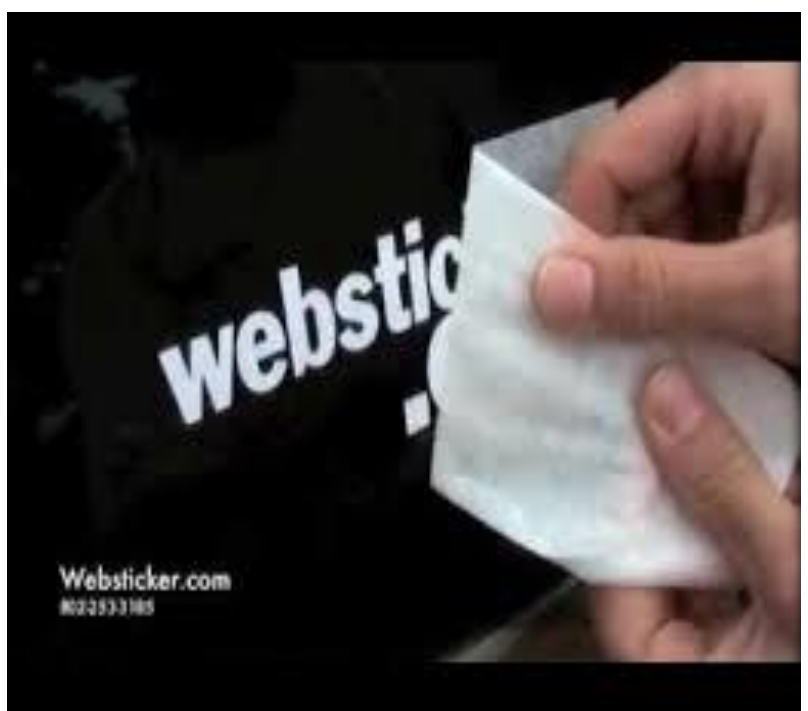

Fig 9:- Shows vinyl sticker design being transferred onto a vehicle surface

(Source: www.stickeryou.com)

This style or method of vehicle branding is very common in the society nowadays due to the competitive markets. A vehicle either four wheel or three wheel is wrapped with the vinyl design and then wrapped on either the whole body of the vehicle or half wrapping. This style of branding is mostly done during promotions of company's products as it is very common in Ghana and other part of Africa. The product and the name of that company is designed and printed on a vinyl material as a means of easy display on vehicles

\section{Metal Impression Branding}

The metal impression branding unlike the other methods, make use of a designed logo, emblem, any abstract or letters representing a company or institution in metal and with the help of any reliable adhesive material, fixed on the surface of an automobile. The metal identification for branding can be fixed from the bumper to the corner of a vehicle's windscreen. Metals that can be used for this branding method include brass, aluminum, zinc, lead, copper, nickel, iron, silver, stainless steel etc. these are well designed for the purpose of visibility and given a good finish to be able to be recognized from afar. examples are shown in figures 8, 9 and 10 .

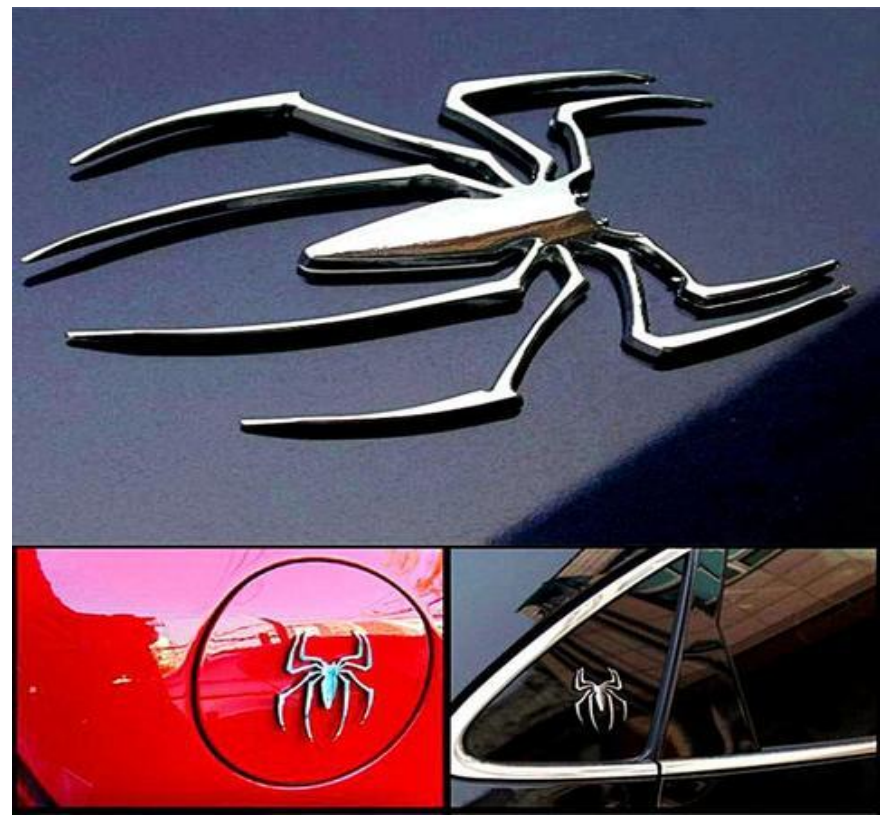

Fig 10:- Shows a 3D metal Spider sticker on a vehicle

(Source: $\underline{w w w . m a r k e t 14 . c o m}$ ) 


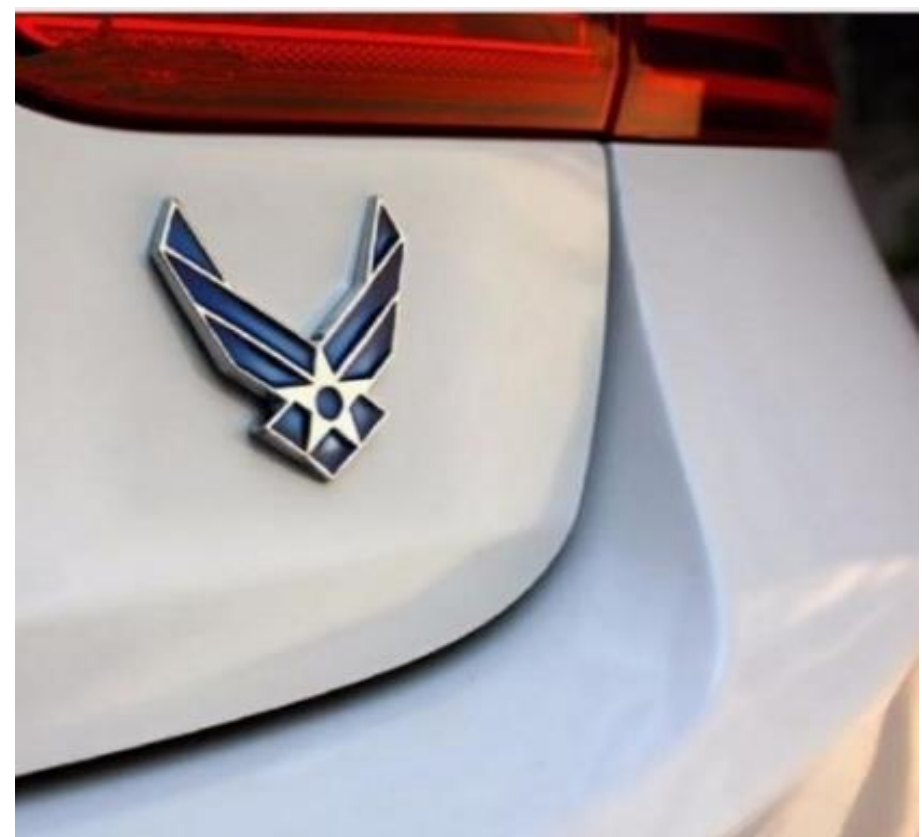

Fig 11:- Shows an air force Chrome metal emblem badge (Source: www.collectionfast.org)

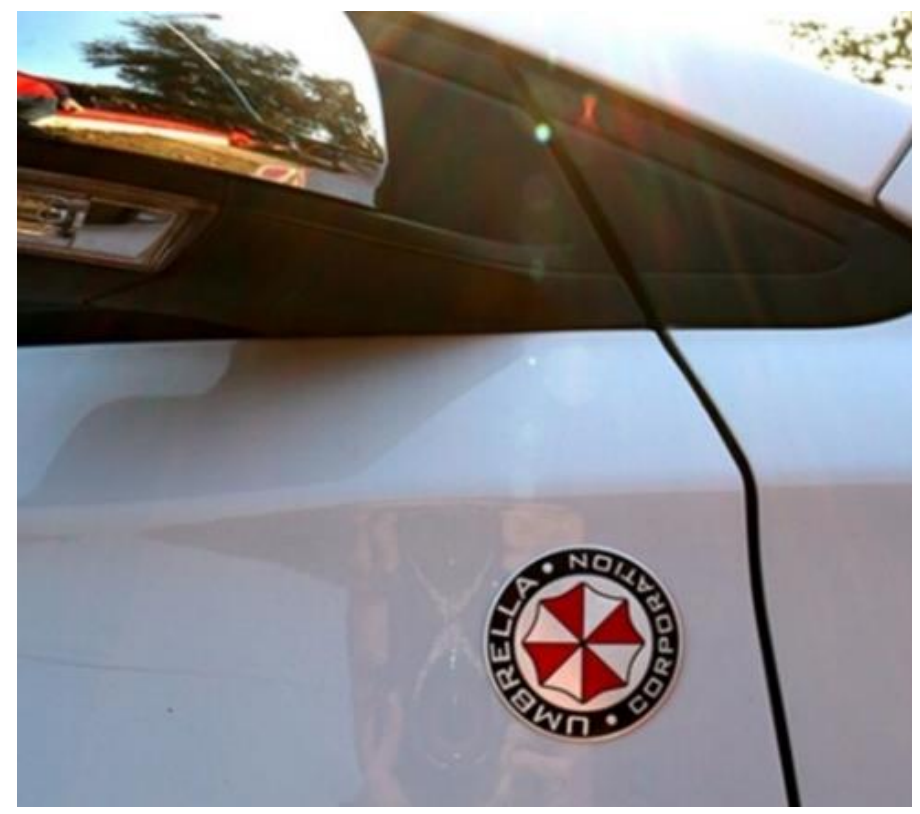

Fig 12:- Shows a 3D evil umbrella emblem badge on a corner of a on a vehicle car door (Source: www.aliexpress.com)

Modern metal impression branding is done in such a way that the branding (design for advertisement or recognition purposes) can be detached or changed due to the dynamic nature of the world or the changes of moment to suit present innovations and creativity. Like vinyl branding on vehicles that can be removed without leaving any stains on the surface pasted on, so can metal impression branding on vehicles be done. Whether the metal impression for the branding was glued to the bumper, doors or even to the windscreen, that strong adhesive used can be detached from the vehicle body.

\section{CONCLUSION}

It can be concluded that the predominant approach to branding vehicles in Ghana. These are vinyl graphics branding and metal impression branding. The study again substantiates that, the basic materials for the three vehicle branding methods are metal, polyvinyl chloride and magnetic materials. From both universities, the study also reveals that the most commonly used method of branding in descending order were vinyl graphics, metal impression and magnetic branding. These are summarized in table 2 . 


\begin{tabular}{|c|c|}
\hline Method of branding & Materials employed \\
\hline $\begin{array}{c}\text { Vinyl Graphics } \\
\text { branding }\end{array}$ & Polyvinyl chloride materials \\
\hline $\begin{array}{c}\text { Metal impression } \\
\text { branding }\end{array}$ & Metal \\
\hline Magnetic branding & $\begin{array}{c}\text { Polyvinyl chloride materials and } \\
\text { magnetic bar }\end{array}$ \\
\hline
\end{tabular}

Table 2:- Method vehicle branding in Ghana

\section{RECOMMENDATION}

The study recommends that regular observation should continue to in various intuitions and organization to either confirm or improve the knowledge shared through this paper. It is also recommended that the vinyl graphic printing approach should adopt more permanents impression since they are gradually become a temporal means. Moreover, the use of the vinyl materials in their true colours through superposition, superimpositions and juxtapositions will creation a more permanents impression. Furthermore, upcoming design of vehicles' tags should make room for electronic chips since they are gradually penetrating the system of vehicle identification. This is evident in Electronic vehicular access system s observed in both institutions. Lastly this study also recommends further study into the type of the materials identified and their best application to boost the quality of brandings.

\section{REFERENCES}

[1]. Business dictionary (2017) 'Branding' [Online] Available at: www.businessdictionary wordmeaning.com [Accessed December,2017]

[2]. Davis, M. (2009). Fundamentals of Branding. England: Fairchild Books.

[3]. Schmidt, P. (2005). What is Branding: Graphic Design Handbook. England: Rockport Publishers, England.

[4]. Shimp, A.T., (2008). Advertising Promotion and other aspect of Integrated Marketing Communication. Thousand Oaks, CA, Sage.

[5]. Perry, D. (2013). Branding your Vehicle: The ultimate guide. Handyman Startup, Para 14-17.

[6]. Wong, L. (2005). Brand Think. Trafford: Trafford Publications. 